\title{
AVALIAÇÃO DA QUALIDADE DOS SERVIÇOS PRESTADOS POR UMA CASA LOTÉRICA DE CAJAZEIRAS/ PB, NA PERCEPÇÃO DO CLIENTE
}

\section{EVALUATION OF QUALITY OF SERVICES OFFERED BY A HOUSE LOTTERY OF CAJAZEIRAS / PB, NA CUSTOMER PERCEPTION}

\section{D0I: http://dx.doi.org/10.21714/raunp.v9i1.876}

\section{Armistrong Martins da Silva}

Administrador. Mestre em Engenharia de Produção. Professor MsC. da Universidade Potiguar - UnP.

E-mail: armistrongmartins@gmail.com

\section{João Bosco Almeida Freire}

Graduando do Curso de Bacharelado de Administração da Faculdade São Francisco da Paraíba - FASP

E-mail: trevodasortecajazeiras@gmail.com

Envio em: Julho de 2014

Aceite em: Janeiro de 2017

\section{RESUMO}

Este trabalho tem por objetivo avaliar a qualidade dos serviços oferecidos por uma casa lotérica localizada no município de Cajazeiras-PB, na percepção dos clientes. A partir da opinião dos clientes é possível tomar conhecimento de situações até então desconhecidas por parte da empresa e propor soluções que ajudem a melhorar a qualidade dos serviços prestados ao consumidor. Em relação aos aspectos metodológicos utilizados, 0 artigo tem um caráter qualiquantitativo, baseada nas pesquisas bibliográfica, exploratória e descritiva. Os resultados da pesquisa mostrou que 0 índice de aprovação da qualidade dos serviços prestados pela empresa é maior evidente nas dimensões: Confiabilidade (75,39\%), Responsividade (85,71\%), Segurança (82,54\%) e Empatia $(85,72 \%)$ que obtiveram o maior conceito de qualidade segundo a percepção dos clientes pesquisados, constatando, em parte, pelo público usuário pesquisado a credibilidade da qualidade nos serviços prestados pela Casa Lotérica, no tocante a estes requisitos. Os Aspectos Tangíveis (68,36\%) obteve o menor conceito na percepção dos clientes quanto à qualidade dos serviços ofertados, merecendo melhor atenção dos gestores da Casa Lotérica estudada, no intuito de minimizar os resultados negativos e maximizara a qualidade contínua dos serviços prestados pela empresa.

Palavras-chaves: Qualidade. Qualidade em Serviços. Percepção de clientes.

\section{ABSTRACT}

This work aims to evaluate the quality of services offered by a lottery home located in the municipality of Cajazeiras-PB, the perception of customers. From the view of customers can become aware of situations previously unknown by the company and propose solutions that help improve the quality of services provided to consumers. In relation to the methodological aspects used, the article has a quali-quantitative character based on literature, exploratory and descriptive research. The survey results showed that the approval rating of the quality of services provided by the company is evident in higher dimensions: Reliability (75.39\%), responsiveness $(85.71 \%)$, Security $(82.54 \%)$ and Empathy $(85,72 \%)$ which had the highest concept of quality as perceived by the customers surveyed, noting, in part, by public users researching the credibility of the quality of services provided by the Lottery Agency, regarding these requirements. The tangible aspects (68.36\%) had the lowest concept in the perception of customers regarding the quality of services offered and deserves better attention from managers Lottery Agency studied in order to minimize the negative and maximize the ongoing quality of services provided by company.

Keywords: Quality. Quality Services. Customer perception. 


\section{INTRODUÇÃO}

Toda organização deve constantemente passar por uma auto avaliação e, consequentemente, identificação dos seus problemas internos, assim como os externos para verificar se os serviços prestados aos seus consumidores estão dentro dos padrões de qualidade e satisfazem as necessidades tanto da empresa, quanto dos clientes.

Neste contexto, ao se tratar de qualidade sob a perspectiva dos usuários é possível perceber que as expectativas podem variar de consumidor para consumidor. Ou seja, a forma que os clientes "percebem" a qualidade de um produto ou a prestação de um serviço pode variar para diferentes clientes.

No caso dos serviços, as percepções podem variar ainda mais, pelo fato dos serviços serem intangíveis, isto é, não podem ser tocados, o que implica na interpretação subjetiva do consumidor. Além disso, a própria tendência de variabilidade dos serviços pode fazer com que um mesmo cliente tenha percepções diversas do mesmo serviço em diferentes ocasiões.

Sobre este assunto, são esclarecedoras as palavras de Slack et al. (2009) as quais mostram que, mesmo sendo esse conceito um referencial primário na prestação de serviços não se tem um consenso comum entre os autores que já se dispuseram a tratar da temática da qualidade em serviço.

Diante disso, as casas lotéricas, objeto deste estudo, oferecem um serviço básico e atendem a todos os públicos-alvo, devendo transparecer o máximo de conforto, confiança, segurança e credibilidade aos seus clientes. Desta forma, deve então preocupar-se em atender a alguns requisitos como a acessibilidade e condições que ofereçam bem-estar aos seus clientes.

Um dos mecanismos utilizados para avaliar a percepção dos usuários dos serviços prestados pelas empresas que atuam no setor de correspondentes bancários se baseia em um mecanismo conhecido como feedback, que consiste em dar uma resposta a um pedido ou acontecimento, termo muito utilizado nas áreas de Administração de Empresas, podendo acarretar valores positivos ou negativos. A partir desse mecanismo é possível tomar conhecimento de situações até então desconhecidas por parte da empresa e propor soluções que ajudem a melhorar a qualidade dos serviços prestados ao consumidor.

Desse modo, Maximiano (2012, p. 129) deixa claro que o papel da administração da qualidade é procurar garantir a satisfação do cliente e ao mesmo tempo garantir os interesses econômicos da empresa. Diante disso, a satisfação dos clientes é um objetivo prioritário para todas as organizações, uma vez que sem clientes satisfeitos as demais medidas de desempenho da organização ficam comprometidas.

Um dos segredos da qualidade é a organização da empresa quanto ao controle das suas atividades, ou seja, a qualidade implica no fato da empresa conhecer muito bem todos os setores que a compõe chegando até os clientes, que, por sua vez, também devem estar nos planos da empresa, através da busca pela satisfação de suas necessidades.

Diante dessa realidade, é importante então a empresa que oferece serviços se abrir para críticas e opiniões dos usuários e através dessas opiniões se consiga identificar as verdadeiras necessidades dos usuários desses serviços que oferece. Esse julgamento então leva novas ideias à direção ou gerência da empresa a fim de melhorar o atendimento - trazendo benefícios ao cliente e à empresa, através da lucratividade. Assim, a qualidade depende de todos os setores organizacionais da empresa, inclusive do cliente que deve contribuir para um fluxo contínuo e ágil das ações da empresa.

No setor de correspondente bancário a importância da avaliação dos serviços prestados pelas empresas não é diferente. Considerando que pagar as contas é uma tarefa obrigatória a todos os cidadãos, as empresas, casas lotéricas e pontos de atendimento responsáveis por recolher pagamentos e realizarem apostas devem oferecer serviços de qualidade aos seus clientes, garantindo que as necessidades dos solicitantes sejam as suas.

Logo, a pesquisa desenvolvida tem como objetivo levantar dados e fazer uma análise da percepção dos clientes em relação à qualidade dos serviços prestados por uma casa lotérica, localizada no município de Cajazeiras/PB, identificando na análise, como os cidadãos estão preferindo pagar suas contas e qual o modo de atendimento desejado, além de abrir espaço para críticas e sugestões.

Logo, o problema que será abordado nesse trabalho surge da indignação com a qualidade dos serviços prestados por uma casa lotérica e do conflito que se faz na prestação de alguns serviços de maneira equivocada ou mesmo incorreta.

Para tanto, coloca-se como problema de pesquisa, o seguinte questionamento: Qual a percepção dos clientes, quanto à qualidade dos serviços prestado por uma Casa Lotérica, localizada na cidade de Cajazeiras/PB? 
Sendo assim, estes trabalho está estuturado da seguinte maneira, inicia-se com a introdução no qual estão presentes os requisitos básicos para o desenvolvimento do tema; Seguido da Revisão da Literatura, abordando temas sobre à Qualidade em Serviço e suas dimensões. Nos aspectos metodológicos da investigação, são demonstrados os métodos e as técnicas aplicáveis, utilizadas nas fases da elaboração da pesquisa. São apresentados também, os resultados e a análise da pesquisa de campo, identificando a classificação da qualidade dos serviços ofertados pelo correspondente bancário, de acordo com a percepção dos clientes.

Finaliza-se com os aspectos conclusivos do trabalho, considerando o alcance dos objetivos propostos com seus benefícios e contribuições para essa área de estudo, bem como, as recomendações e sugestões para serem futuramente implementadas pelo gestor da casa lotérica.

\section{FUNDAMENTAÇÃO TEÓRICA}

\subsection{QUALIDADE NAS ORGANIZAÇÕES}

O conceito de qualidade nas organizações não é algo novo, embora a princípio não houvesse uma noção clara do que fosse qualidade, esta noção foi evoluindo ao longo do tempo em função das especificidades que cada período apresentou na história do desenvolvimento humano. Em concordância com esse contexto, Juran (1993) citado por Silva, Correia e Idrogo (2007) observam que as necessidades humanas pela qualidade existiram desde os princípios da história. Ao longo dos séculos as estratégias de gerenciamento para qualidade sofreram mudanças contínuas em reposta às contínuas mudanças nas forças políticas, sociais e econômicas das organizações.

No entanto, a qualidade nas últimas décadas tem se tornado um condicionante de primeira necessidade na fabricação de produtos e prestação de serviços. A Teoria Geral da Administração, na visão de Maximiano (2012), explica bem sua evolução, como também sua importância nas organizações. Quando uma organização se preocupa em oferecer produtos ou serviços com qualidade, deve conscientizar-se que existem padrões para a sua produção ou prestação, na ideia de que este irá contribuir positivamente e de forma segura. De nada adiantaria um produto ou serviço que atendesse a todas as obrigações e especificações ordenadas sem que atendesse a necessidade real do usuário, pois assim este teria um campo de opções que não permitiriam uma escolha fixa.

Desta forma, qualidade nas organizações significa: rápida percepção e satisfação do cliente das necessidades do mercado, adequação ao uso dos produtos e homogeneidade dos resultados do processo (ISHIKAWA, 1997, p.35).

Atualmente, um número crescente de empresas reconhece que o investimento em qualidade é um dos mais lucrativos que se pode fazer, uma vez que investir em qualidade representa redução de defeitos, fabricação de melhores produtos, melhora o bem estar dos clientes externos e internos, proporcionam maiores lucros para a organização e garante uma maior satisfação dos clientes.

Diante dessa realidade, Oliveira $(2012$, p. 23) afirma que os negócios atualmente estão direcionados para a competitividade, o que significa que as organizações devem-se dirigir para técnicas e conceitos, cada vez em maior quantidade, sobre a qualidade, direcionadas para as empresas como um todo, Isso acaba não só envolvendo a produção de um produto ou serviço, como também as etapas que tratam de sua viabilização. E é nesse ponto que entra a gestão mais abrangente da organização.

Deste modo, os autores afirmam que na gestão administrativa voltada para a qualidade atual há uma preocupação com o aumento da satisfação e confiança dos clientes, aumento da produtividade, redução dos custos internos, melhora da imagem e dos processos de modo contínuo e a possibilidade de acesso mais fácil a novos mercados, descentralizando a atenção na produção do produto ou serviço, pois o segredo para um desempenho do processo com sucesso é oferecer condições plausíveis em todos os fatores do conteúdo.

Ainda, de acordo com os princípios da Qualidade Total, uma nova visão do campo organizacional foi estabelecida. Nela, o gerente fica responsável por transformar a empresa num ambiente pessoal e familiar aos seus funcionários. Assim, o funcionário sente-se realmente parte da empresa preocupando-se com os eventuais problemas e se satisfazendo dos sucessos alcançados por ela. Sente também a necessidade de aperfeiçoar-se para atender melhor não somente a clientela, mas também o restante dos membros da empresa, com a intenção de elevar seu cargo e respectiva importância por meio da confiança e segurança que a empresa pode lhe propor.

Neste contexto, Oliveira (2012), afirmam que, implantar a qualidade implica em adquirir gastos necessários para a reforma da infraestrutura da empresa, uma vez que a qualidade corresponde à correção de 
erros de produtos com defeitos, à simplificação e à racionalização de procedimentos de tarefas e à agilização da comercialização dos produtos. Por esses motivos, a qualidade refere-se a padrões de procedimentos que visam adequar e uniformizar os produtos, tendo em vista sua aceitação pelo consumidor/cliente, com atenção de torna-lo cativo e fiel no consumo.

Portanto, um produto ou serviço com qualidade, para alcançar sucesso não precisa agregar o maior número de benefícios possíveis, ele apenas precisa cumprir sua função atendendo a necessidade do cliente sem apresentar erros no processo, com limites que permitem uma tolerância desses erros na estrutura ou número de processos.

\subsection{QUALIDADE EM SERVIÇOS}

Na concepção de Paladini (2004), o termo serviço pode ser definido como uma ação desenvolvida por terceiros, em atendimento a solicitação explícita, específica e bem definida de um usuário determinado. Em geral, esses terceiros habilitam-se a realizar o serviço por possuírem qualificação própria (em maior ou menor grau de especificação) para tanto.

De um ponto de vista simplificado, o termo "serviço" pode ser definido como qualquer atividade econômica que não resulta na produção direta de bens tangíveis ou na extração de recursos naturais. Para que se entendam melhor os serviços, deve-se ter como base que, os serviços diferem dos produtos industriais por atender algumas características específicas como: a intangibilidade, por não poder ser estocado e não ter um tempo médio de vida; e ainda, por envolver a participação direta das pessoas no processo (SILVA; CORREIA; IDROGO, 2007).

De acordo com os autores supracitados, é válido observar que os serviços possuem dois componentes de qualidade que devem ser considerados; os serviços propriamente ditos, e a forma como é percebido pelo cliente.

Para a realização de qualquer serviço são necessários certos atributos, ou seja, o detalhamento do que se precisa para proporcionar serviços com qualidade. Estes atributos podem ser vistos de certa forma como requisitos essenciais para que os momentos da verdade ocorram de acordo com o determinado nível de expectativas dos clientes. Os atributos têm certas dimensões, sendo elas principalmente determinadas pela: confiabilidade, segurança, aspectos tangíveis, empatia e receptividade.

Segundo Las Casas (2008, p.7), a percepção dos clientes em relação aos serviços é feita com base em três aspectos físicos: similaridade, proximidade e continuidade. No Princípio da Similaridade ele afirma que as coisas similares tendem a ser percebidas pelo indivíduo como parte de um conjunto, em que as coisas aparentemente iguais fazem parte do mesmo grupo. Já no Princípio da Proximidade o mesmo alega que os conjuntos também podem ser formados pelos elementos mais próximos entre si. Enquanto isso, no Princípio da Continuidade o autor explica que depois de trabalhar um conceito sobre uma marca, o próprio cliente é responsável por construí-la, dando continuidade ao que o anunciante já propôs.

A ideia de Qualidade Total abrange toda a área dos recursos materiais, bem como os recursos humanos, então é necessário matéria-prima de qualidade e mão de obra especializada (treinada), além de um ambiente razoavelmente agradável às pessoas que executam o gerenciamento de todos os setores da empresa, garantindo uma disposição e satisfação maior deles.

Em geral, os conhecimentos sobre qualidade em serviços confundem-se com o de qualidade total. A diferença básica está no fato de que a qualidade de serviço teve origem em alguns países europeus, como Suécia e Inglaterra, carecendo ainda de um conjunto coerente de métodos próprios de trabalho, enquanto que a qualidade total provém do Japão e possui metodologia definida (BRANDÃO JÚNIOR; LIRA; GONÇALVES, 2004, p. 2-3).

Esquecendo a origem dos dois tipos de qualidade, os autores tocam num ponto importante a ser discutido: a Qualidade Total está tentando ser implantada na Qualidade de Serviços, ou seja, o controle sobre todo o processo, desde o momento da apresentação do serviço ao cliente até o momento dos agradecimentos tanto da empresa, pela contratação do serviço, quanto do cliente, pela execução do serviço.

Portanto, é possível observar que o segredo da qualidade nos serviços está no cliente. Este deve ser explorado infinitas vezes, das mais possíveis maneiras. Suas necessidades devem chegar sempre em primeiro lugar, atentando ao fato de que os funcionários contribuem diretamente para isso.

\subsection{DIMENSÕES DA QUALIDADE EM SERVIÇO}

A avaliação da qualidade de um serviço é essencial para a prosperidade de uma empresa, pois sem a constante melhoria de suas atividades o público-alvo tende a procurar serviços melhores na concorrência, 
de forma que possam atender as suas necessidades, e, que possam surpreender em suas ações. Porém, por ser intangível, os serviços se mostram complicados na hora da avaliação, recorrendo a métodos avaliativos abstratos.

Neste contexto, uma das ferramentas mais utilizada para ajudar na avaliação dos serviços prestado pelas organizações é o SERVQUAL, desenvolvido em meados dos anos 1985 pelos pesquisadores Zeithaml, Parasuraman e Berry. A ferramenta é uma estrutura de gestão para medir a qualidade dos serviços de uma empresa frente a um ideal. Eles foram responsáveis pelo desenvolvimento do Modelo dos 5 Gaps (Lacunas) da Qualidade de Serviços:

- O Gap 1: esta relacionado as expectativas do consumidor e as percepções da gerência, uma vez que nem todas as expectativas dos consumidores são consideradas adequadamente pela gerência, o que pode gerar impacto na avaliação da qualidade do serviço pelo consumidor.

- O Gap 2: refere-se as percepções da gerência e as especificações da qualidade dos serviços. A gerência muitas vezes apresenta dificuldade para atender às expectativas dos clientes e superá-las, em razão da dificuldade em estabelecer padrões de desempenho e, em outros casos, pela falta de comprometimento com a qualidade do serviço. Em outra situação, os gerentes podem não ter treinamento suficiente para superar essas questões.

- No Gap 3: são discutidas as especificações da qua- lidade dos serviços e sua entrega. Mesmo quando existem especificações formais para a entrega de um serviço, nem sempre o padrão de qualidade ideal é seguido pelos colaboradores, pois não é fácil garantir o cumprimento integral dos procedimentos quando se trata de uma prestação de serviços que envolve os funcionários. Neste caso, os colaboradores podem também não ter treinamento suficiente.

- O Gap 4: é destinado aa entrega dos serviços e as comunicações externas. Já que as expectativas do consumidor têm um papel central na percepção da qualidade do serviço, é essencial não prometer mais nas comunicações de marketing do que se pode entregar de fato, para não aumentar a expectativa inicial e diminuir posteriormente a percepção de qualidade.

- No Gap 5: destina-se ao serviço percebido e o serviço esperado: o segredo da boa prestação de serviço é atingir e, se possível, superar as expectativas do consumidor em relação ao serviço observando se o cliente está percebendo a qualidade do serviço (SPINA; GIRALDI; OLIVEIRA, 2012).

Através da metodologia desenvolvida é possível verificar os instrumentos de serviços de alta qualidade, que os clientes usam na sua ideia de percepção para a escolha da organização, as quais pretendem usar como prestadora de serviço. Originalmente construíram dez classes desses instrumentos, sendo elas visualizadas no quadro 02 a seguir.

\section{QUADRO 2: DETERMINANTES DA QUALIDADE EM SERVIÇOS}

\begin{tabular}{|l|l|}
\hline \multicolumn{1}{|c|}{ CLASSES } & \multicolumn{1}{c|}{ CONCEITO } \\
\hline Confiabilidade & $\begin{array}{l}\text { Abrange consistência de desempenho e confiabilidade. Também significa que a empresa faz } \\
\text { certo da primeira vez e honra seus compromissos. Exemplos: precisão nas contas, manutenção } \\
\text { dos registros de forma correta e realização do serviço no tempo designado. }\end{array}$ \\
\hline Presteza & $\begin{array}{l}\text { Refere-se ao desejo dos empregados de prover os serviços e à sua presteza nessa tarefa. } \\
\text { Envolve rapidez nos serviços: retornar a ligação de um cliente rapidamente ou realizar } \\
\text { rapidamente um serviço. }\end{array}$ \\
\hline Competência & $\begin{array}{l}\text { Significa possuir a habilidade e o conhecimento necessários para realizar o serviço, o que } \\
\text { envolve: conhecimento e habilidade do setor de atendimento e do suporte operacional, e } \\
\text { capacidade de pesquisa da organização. }\end{array}$ \\
\hline Acessibilidade & $\begin{array}{l}\text { Refere-se à proximidade e à facilidade de contato, o que significa que o serviço pode ser } \\
\text { acessivel por telefone, o tempo de espera para receber o serviço não é extenso, tem horário de } \\
\text { funcionamento e localização convenientes. }\end{array}$ \\
\hline Cortesia & $\begin{array}{l}\text { Envolve delicadeza, respeito, consideração, amabilidade no atendimento pessoal, o que inclui } \\
\text { consideração pela propriedade do cliente. }\end{array}$ \\
\hline
\end{tabular}




\begin{tabular}{|c|c|}
\hline CLASSES & CONCEITO \\
\hline Comunicação & $\begin{array}{l}\text { Manter os consumidores informados em linguagem que possam entender e ouvi-los. Isso } \\
\text { significa aumentar o nível de sofisticação com os mais bem-educados, falar de maneira simples } \\
\text { e direta com os consumidores mais simples, explicar o serviço em si, o preço, os descontos, e } \\
\text { garantir ao consumidor que um eventual problema será resolvido. }\end{array}$ \\
\hline Credibilidade & $\begin{array}{l}\text { Envolve honestidade e comprometimento no atendimento das necessidades dos clientes, } \\
\text { abrangendo nome e reputação da empresa, características pessoais dos atendentes e nível de } \\
\text { envolvimento nas interações com os clientes. }\end{array}$ \\
\hline Segurança & Ausência de perigo, risco ou dúvida envolvendo segurança física, financeira e confidencial. \\
\hline $\begin{array}{l}\text { Compreensão e } \\
\text { conhecimento do cliente }\end{array}$ & $\begin{array}{l}\text { Esforçar-se para entender as necessidade e exigências específicas dos clientes, prover } \\
\text { atenção individual e reconhecer os clientes habituais. }\end{array}$ \\
\hline Aspectos tangíveis & $\begin{array}{l}\text { Inclui as evidências físicas do serviço: instalações aparência do pessoal, ferramentas e } \\
\text { equipamentos usados na prestação de serviço, representações físicas do serviço e outros } \\
\text { clientes presentes nas instalações. }\end{array}$ \\
\hline
\end{tabular}

Fonte: Adaptado de Parasuraman, Zeithaml e Berry, (1985).

Mais tarde essas 10 (dez) classes foram resumidas a 5 (cinco) fatores denominados Dimensões da Qualidade:

1. Aspectos Tangíveis: materiais utilizados na prestação dos serviços. Bens objetivos, concretos, tocáveis;

2. Confiabilidade: capacidade de fazer com que o cliente sempre tenha a empresa como primeira opção de escolha pela sua responsabilidade com o cliente;

3. Segurança: capacidade que o atendente tem de transmitir segurança ao cliente ao ponto de torná-lo seguro também;

4. Empatia: capacidade que o atendente tem de se colocar na condição do cliente e resolver a sua situação problema como fosse a sua;

5. Responsividade: capacidade de compreensão do atendente para com o cliente, visando o apoio emocional, através da bidirecionalidade na comunicação, favorecendo o desenvolvimento da autonomia e da autoafirmação entre ambas as partes.

Diante do exposto, é possível observar que os clientes cultuam estas cinco dimensões para fazerem suas analises em relação à qualidade nos serviços, comparando e estudando a relação entre o serviço esperado e o serviço percebido, a distinção entre uma e outro é o resultado positivo ou negativo desta analise. Deste modo, as cinco dimensões da qualidade propostas pelos autores, se encaixam na natureza dos serviços, quais sejam: o desempenho como beneficio primário desejado pelos clientes; e a qualidade per- cebida em que a prestação de um serviço, exige, em muitos casos, a participação do cliente, originando preocupações em nível da qualidade da relação que se estabelece durante o processo de produção e utilização do serviço (PINHEIRO, 2012).

A qualidade nos serviços conduz a satisfação de clientes, fortalecendo o relacionamento e conduzindo a longevidade da interação entre o cliente e a organização. Portanto, a satisfação dos consumidores devem ser uma das primícias a ser alcançadas pelas organizações que prestam serviços, a qual deve ser vista sob quatro perspectivas: a satisfação como sendo uma busca individual; a sua competitividade e o seu lucro; o mercado como um todo; e a visão da sociedade considerando a o consumidor como um cidadão.

\section{PROCEDIMENTOS METODOLOGICOS}

Esta pesquisa é classificada, quanto ao tipo, como uma pesquisa cientifica, por se tratar de um estudo que busca descobrir respostas para um problema mediante a utilização de procedimentos científicos.

Tomando por base os conceitos de Silva e Menezes (2005), para classificar uma pesquisa científica, os procedimentos metodológicos delineados precisam ser fundamentados a partir de quatro aspectos: quanto à natureza, quanto à forma de abordagem do problema, quanto aos objetivos e quanto aos procedimentos técnicos.

Em relação à natureza deste estudo, o mesmo pode ser classificado como sendo uma pesquisa apli- 
cada, na qual, segundo Silva e Menezes (2005), a mesma objetiva gerar conhecimentos para a aplicação prática, dirigida a soluções de problemas. Além disso, envolve verdades e interesses locais. Ou seja, a Pesquisa aplicada, apresentam contribuições práticas decorrentes do conhecimento puro. Uma pesquisa sobre problemas práticos pode conduzir à descoberta de princípios científicos. A partir dessa pesquisa busca-se compreender melhor a percepção dos clientes quanto a Qualidade dos serviços prestados por uma Casa Lotérica, localizada na cidade Cajazeiras/PB.

Quanto à forma de abordagem do problema, o presente trabalho representa uma pesquisa de caráter qualitativo e quantitativo.

Segundo Silva e Menezes (2005), a pesquisa qualitativa não procura enumerar e/ou medir os eventos estudados, nem necessariamente empregar instrumentos estáticos na análise dos dados. Ou seja, parte de questões ou focos de interesses amplos, que vão sendo definidos à medida que o estudo vai avançando. Envolve a obtenção de dados descritivos sobre pessoas, lugares e processos interativos pelo contato direto do pesquisador com a situação estudada, procurando compreender os fenômenos segundo a perspectiva dos sujeitos participantes do estudo.

Além disso, será utilizada a pesquisa quantitativa, que segundo Marconi e Lakatos (2008) a mesma cuida de quantificar dados, opiniões, informações com a utilização de recursos técnicos estatísticos, desde os mais simples como: porcentagem média, mediana e desvio padrão, até o uso mais complexo como coeficiente de correlação, regressão, etc. $\mathrm{O}$ método quantitativo será adotado, pois a coleta de dados será constituída de perguntas fechadas, sendo um procedimento sistemático para a descrição e explicação do estudo em questão.

O presente trabalho situa-se na categoria de Pesquisa Exploratória, uma vez que, este tipo de estudo visa proporcionar um maior conhecimento para o pesquisador acerca do tema ou problema de pesquisa em perspectiva, estabelecendo uma situação favorável ao processo de tomada de decisão. Complementando, Gil (2006) acrescenta que esse tipo de pesquisa se caracteriza pelo desenvolvimento e esclarecimento de ideias, com o objetivo de oferecer uma visão panorâmica e uma primeira aproximação a um determinado fenômeno que é pouco explorado.

Além disso, esse estudo se enquadra na Pesquisa Descritiva, dado que este tipo de pesquisa, segundo informações de Gil (2006), além de envolver verdades e interesses locais, objetiva gerar conhecimento para aplicação prática em soluções de problemas específicos. Neste caso, esta pesquisa visa descrever a realidade da Qualidade dos serviços prestados por uma Casa Lotérica, localizada na cidade Cajazeiras/ $\mathrm{PB}$, na percepção dos clientes.

Para responder ao problema geral formulado pela pesquisa, o método de abordagem adotado foi o método indutivo, no qual o pesquisador colhe informações, examina cada caso separadamente e tenta construir um quadro teórico geral. $\mathrm{O}$ método pode ser entendido como um plano de ação, formado por um conjunto de etapas e procedimentos destinados a realizar e antecipar uma atividade na busca de uma realidade.

Para esse estudo, foram utilizados dados primários e secundários, obtidos em duas etapas distintas e procedimentos técnicos diferentes. Inicialmente, foram coletados os dados secundários por meio de Pesquisa Bibliográfica, que de acordo com Gil (2006), a mesma é feita a partir de materiais elaborados, já publicados, a exemplo de livros, revistas, jornais, artigos científicos e dissertações disponíveis em sites da Internet e bibliotecas, com o intuito de dar embasamento teórico e cientifico a pesquisa.

Os dados primários foram conseguidos por meio da Pesquisa de Levantamento, que é caracterizada, segundo Gil (2006), pela investigação direta com pessoas para conhecer-lhes o comportamento, acerca de um determinado problema.

O instrumento utilizado na coleta de dados será um questionário, que após sua aplicação, seus dados serão categorizados, quantificados e agrupados visando contribuir para o conhecimento do estado atual em relação à percepção do cliente quanto a Qualidade dos serviços prestados por uma Casa Lotérica, localizada na cidade Cajazeiras/PB, buscando identificar suas principais variáveis e servindo de base para a tomada de decisão referente ao desenvolvimento do tema.

O modelo de escala adotado é a "Escala de Likert" na qual os pesquisados responderão a cada quesito, por intermédio de vários graus de concordância. $\mathrm{O}$ nível de concordância dos questionários em relação aos fatores investigados foi enumerado através de uma escala formada por cinco pontos equidistantes, sendo $1^{\circ}$ e $2^{\circ}$ pontos correspondentes à discordância ou insatisfação, o $3^{\circ}$ correspondente à neutralidade ou indiferença, o que se pode considerar como um ponto imparcial ou negativo, e o $4^{\circ}$ e $5^{\circ}$ pontos correspondentes ao nível de concordância ou satisfação. A escala adotada contribuiu para codificar as declarações, qualificadas e revertê-las, por intermédio da 
técnica de análise de conteúdo, em dados qualitativos e quantitativos para posteriormente, receberem o tratamento estatístico adequado.

$\mathrm{O}$ modelo adotado para a pesquisa foi adaptado de Parasuraman, Zeithaml e Berry (1985 apud SILVA; CORREIA; HIDROGO, 2007). O instrumento utilizado na coleta dos dados foi um questionário contendo 20 (vinte) perfuntas, referente às seguintes dimensões: Confiabilidade, Responsividade, Segurança, Empatia e Aspectos tangíveis.

É importante salientar que antes de aplicar o questionário, foi realizado um pré-teste com a participação de 03(três) clientes da Casa lotérica, e como não houve duvidas em relação à interpretação das questões apresentada, não foi necessário fazer modificações ou substituições. Apos o pré-teste, foi realizada a coleta de dados com uma amostra aleatória de 126 clientes consumidores dos serviços ofertados pelo correspondente bancário, realizado durante o expediente, no período de 25/04/2014 a 25/05/2014.

\section{APRESENTAÇÃO DOS RESULTADOS}

Nesta seção, além da apresentação dos resultados será demonstrada a caracterização da empresa estudada, considerando que o processo de aplicação da qualidade em qualquer organização que se dispõe a oferecer serviços com excelência, visa buscar e interpreta a opinião dos clientes. Deste modo, para atender aos objetivos delineados para este trabalho foi elaborado um diagnostico qualitativo, levantado por meio de dados quantitativos, sobre os serviços prestados por uma Casa Lotérica, localizada no município de Cajazeiras/PB, segundo a percepção de seus clientes.

\subsection{CARACTERIZACÃO DA EMPRESA ESTUDADA: CASA LOTÉRICA}

A Loteria estudada tem como nome fantasia Loteria Trevo da Sorte e é credenciada pela Caixa Econômica Federal. A mesma está localizada na Praça Coronel Emídio Cartaxo, $n^{\circ}$ 60, Centro da cidade de Cajazeiras/PB e conta com 03 colaboradores e o gerente, totalizando 04 funcionários. Seus principais serviços prestados são o recolhimento, pagamentos de contas e realização de apostas.

A área de atuação da Casa Lotérica é a região da cidade de Cajazeiras, pertencente ao estado da Paraíba, localizada na Mesorregião Sertão (interior desse estado), distante a $498 \mathrm{Km}$ da capital do estado, João Pessoa. A cidade tem uma área geográfica de aproximadamente 565.899 km2 e uma população de 58.446 habitantes, segundo o Senso 2010, classificando-a como a sétima maior cidade do estado da Paraíba.

Considerando que pagar contas é uma tarefa obrigatória a todos os cidadãos, as empresas, casas lotéricas e pontos de atendimento responsáveis por recolher pagamentos e realizar apostas devem oferecer tal serviço, garantindo o conforto, credibilidade e segurança aos seus clientes. Deste modo a pesquisa teve como objetivo principal avaliar a qualidade dos serviços oferecidos pela casa lotérica, objeto deste estudo, levando em consideração a percepção dos clientes, com o intuito de identificar os fatores positivos e a serem melhorados de acordo com a necessidade dos clientes, construindo assim, um paradigma da qualidade dos serviços prestado pela empresa na região.

Assim, as próximas seções irão abordar os resultados das dimensões da qualidade dos serviços prestados pela Casa lotérica estudada, segundo a percepção dos seus clientes.

\subsection{DIMENSÃO CONFIABILIDADE}

No que se refere ao aspecto Confiabilidade, à maioria dos respondentes, 48 pessoas, que corresponde a $38,09 \%$ concordam totalmente com as informações repassada pelos funcionários da Casa Lotérica. Além destes, 47 entrevistados ou (37,30\%) concordam e confiam nas informações repassadas pela empresa. Deste modo, o grau de concordância total em relação à dimensão Confiabilidade é de $\mathbf{( 7 5 , 3 9 \% )}$ atestando a fidelidade e clareza das informações repassadas pela empresa, fator positivo quanto à qualidade dos serviços prestados aos clientes da empresa estudada.

Como também, a pesquisa mostra que 23 entrevistados ou $(18,25 \%)$ demonstraram neutralidade em relação à dimensão confiabilidade, evidenciando imparcialidade nas informações repassadas.

Ademais, entre os respondentes houve 08 pessoas entrevistadas, sendo 04 que discordaram totalmente e 04 que discordou (3,18\%, respectivamente) das perguntas relativas à confiabilidade das informações repassada pelos colaboradores, o que demonstra um pequeno grau de insatisfação, em ralação a algum dos quesitos abordados no questionário (Ver Gráfico 01). 


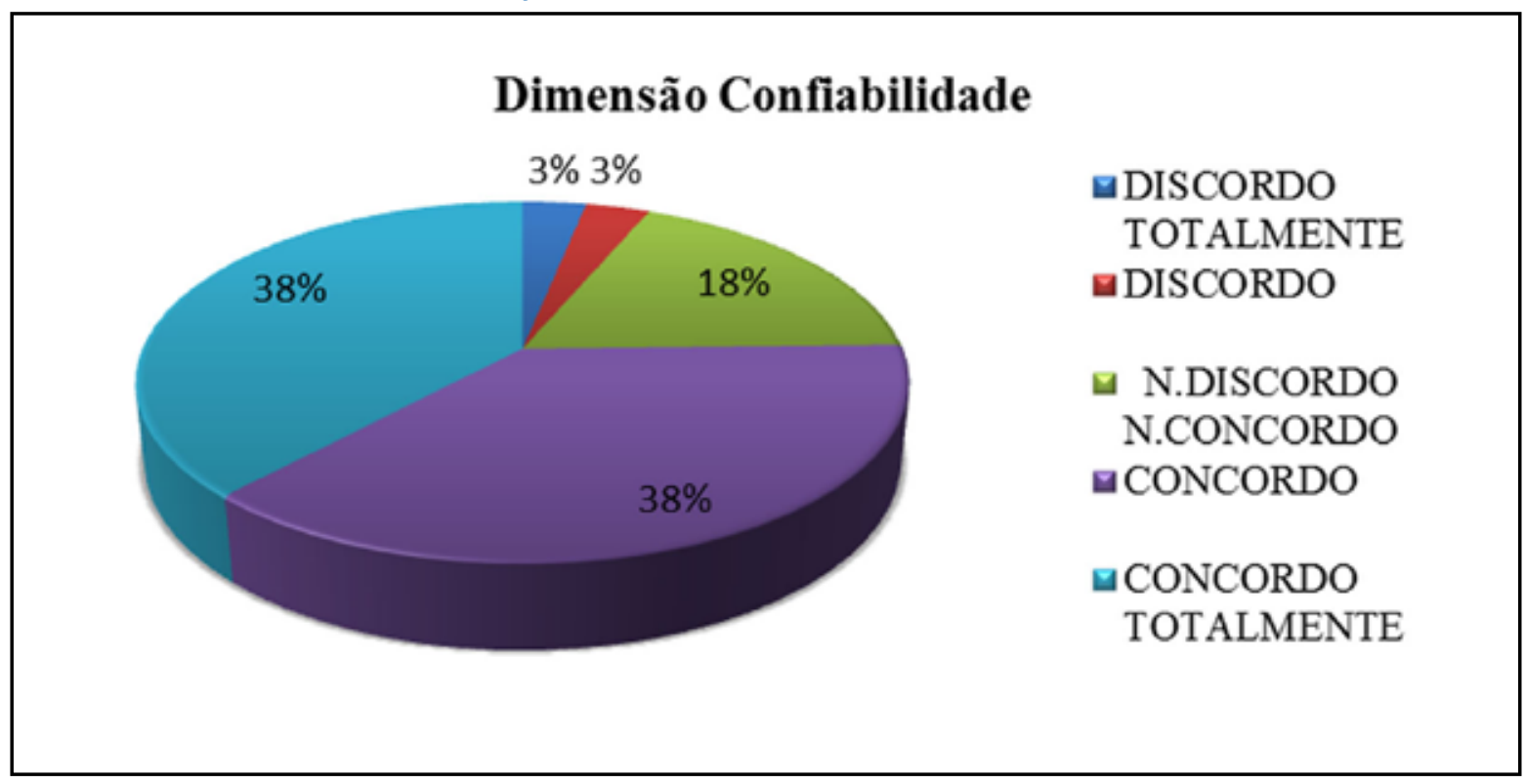

Fonte: Pesquisa direta, (2014).

Os resultados apresentados no Gráfico e Tabela 01 demonstram um grande índice de satisfação dos entrevistados em relação à dimensão confiabilidade, no qual a grande maioria dos respondentes $\mathbf{( 7 5 , 3 9 \% )}$ afirma que os serviços prestados pelos atendentes satisfazem suas exigências; e que a empresa está preparada para solucionar as dúvidas e problemas dos clientes, demonstrando que a mesma está no caminha certo, para o alcance da melhoria contínua da qualidade dos serviços prestados pela Casa Lotérica.

\subsection{DIMENSÃO RESPONSIVIDADE}

No tocante ao aspecto Responsividade, observa-se que mesma é de grande importância para a empresa, uma vez que corresponde aos objetivos propostos e obrigações da empresa, no que ser refere aos incentivos e incorporação de programas de responsabilidade social e ambiental em sua estrutura, a justa remuneração aos seus funcionários, a oferta da qualidade no atendimento, a utilização adequada dos recursos, etc.

Em relação a esta dimensão a maioria dos entrevistados, 75 pessoas $(59,52 \%)$ concorda totalmente com os aspectos referentes à dimensão Responsividade e atuação da empresa estudada. Quando somada ao índice de pessoas que concordam com esta dimensão $(26,19 \%)$, no total, o grau de concordância sobe para quase $\mathbf{8 6 \%}$, atestando a preocupação da empresa para com seus clientes e para comunidade na qual está inserida.

Ademais, os resultados mostram que 14 pessoas, correspondente à $(11,11 \%)$ dos entrevistados demonstraram neutralidade quanto ao quesito avaliado, indicando não saber se há na empresa acessibilidade para pessoas com deficiência e atendimento exclusivos para idosos e gestantes; e apenas 04 respondentes (incluindo os que discordam e discordam totalmente), correspondem a 3,18\% dos entrevistados, divergiram em alguns quesitos relativos à responsividade da Casa Lotérica pesquisada. (Ver Gráfico 02). 


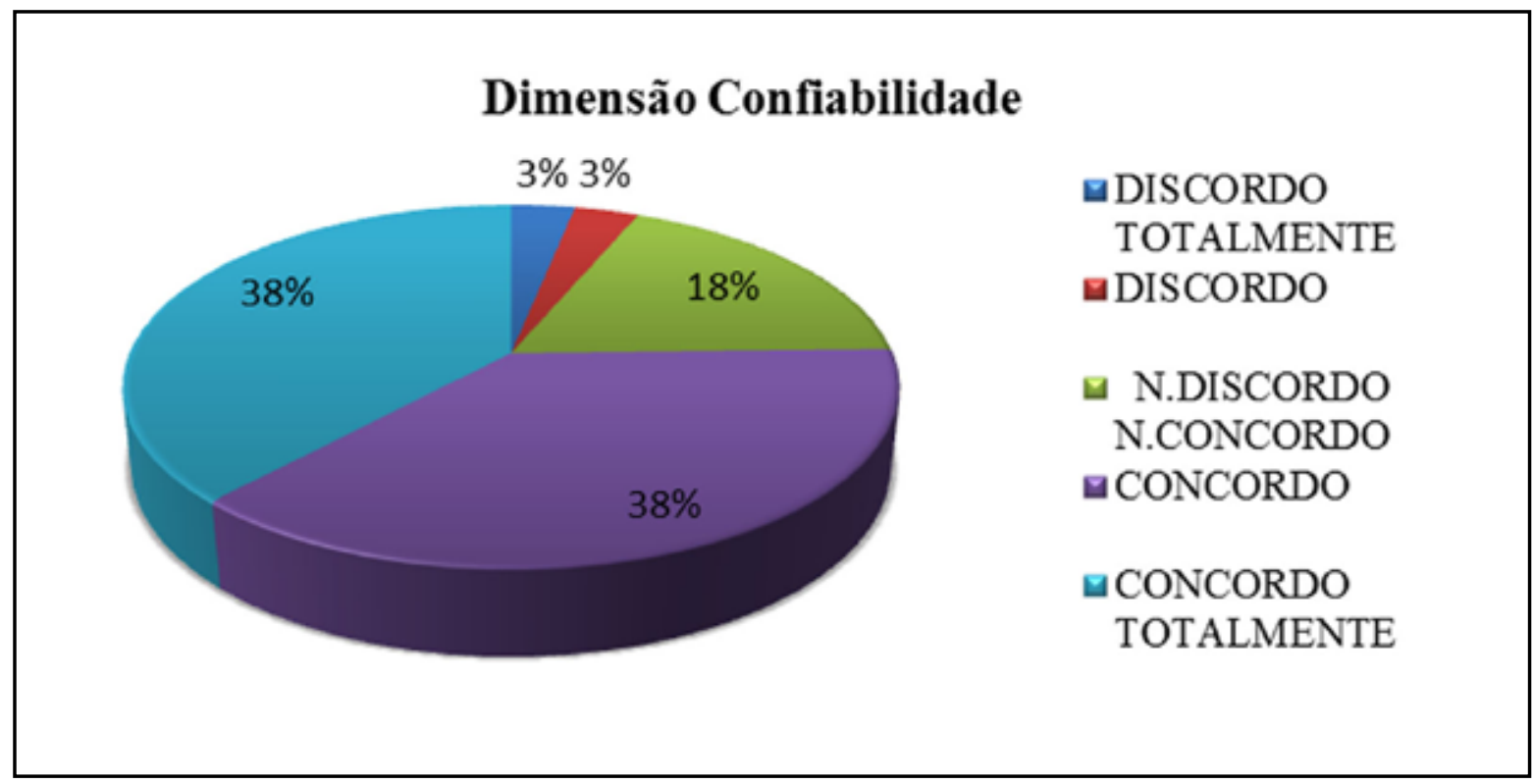

Fonte: Pesquisa direta, (2014).

Em relação à dimensão Responsividade, os resultados denotam a satisfação dos entrevistados em relação à dimensão estudada $(\mathbf{8 5 , 7 1 \%})$, quanto ao comprometimento da empresa para com os clientes internos e externos. No que se refere aos incentivos e incorporação de programas de responsabilidade social em sua estrutura, a oferta da qualidade no atendimento, a utilização adequada dos recursos.

No que diz respeito à melhoria continua, sugere-se é claro, uma melhor atenção por parte da empresa em divulgar aos seus clientes que a empresa oferece serviços de atendimento aos clientes preferenciais (idosos, gestantes e clientes com criança de colo); além de um ambiente com acessibilidade para portadores de deficiência física, para que de forma clara e transparente todos tenha acesso e conhecimento da atuação da empresa perante a sociedade na qual esta instalada. E procurar aperfeiçoar-se ainda mais, para que assim, consiga a satisfação plena dos clientes internos e externos, já que estes fatores são primordiais a uma instituição que busca a excelência na qualidade dos serviços prestados aos seus consumidores.

\subsection{DIMENSÃO SEGURANÇA}

Quanto ao aspecto de Segurança, observou-se que 60 pessoas, correspondente a $(47,62 \%)$ dos entrevistados concordam totalmente que a Casa lotérica pesquisada transmite confiança e segurança para efetuar transações bancárias. Como também, 44 respondentes $(34,92 \%)$ concordam com os quesitos apresentados por essa dimensão analisada, totalizando um grau de concordância de $(\mathbf{8 2}, \mathbf{5 4 \%}$ ) quanto à segurança dos serviços prestados pela empresa.

Ademais, há uma indicação de neutralidade $(15,87 \%)$, no qual 20 entrevistados preferiram não opinar sobre esta dimensão. E apenas 02 pessoas $(1,59 \%)$, discordaram da competência e confiabilidade das transações feitas na organização, como pode ser observada no Gráfico 03. 


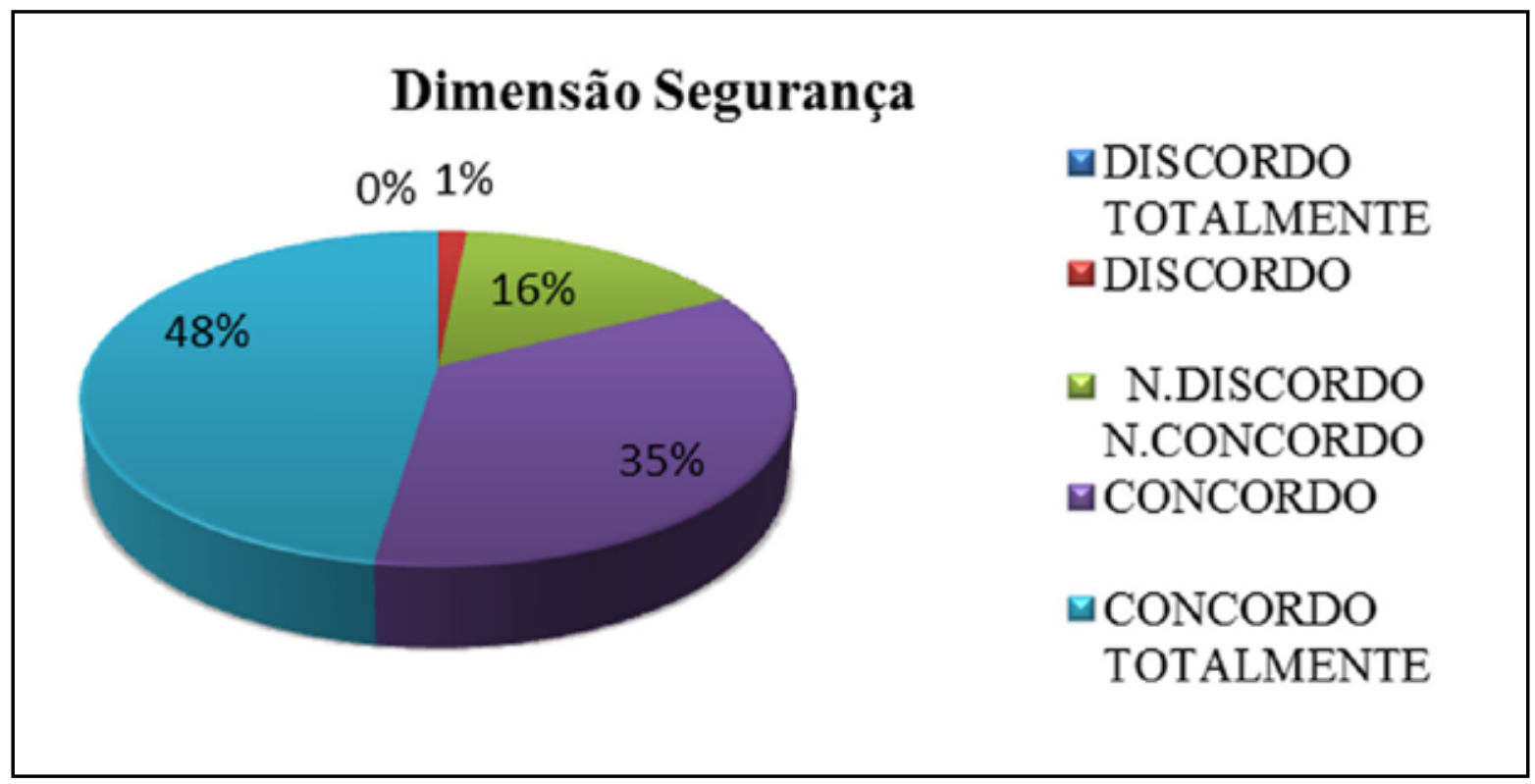

Fonte: Pesquisa direta, (2014).

Ao analisar os resultados apresentados quanto a Dimensão Segurança, foi observado que houve uma concordância de $\mathbf{8 2 , 5 4 \%}$ dos entrevistados em relação à segurança, competência e responsabilidade da organização na prestação dos serviços aos clientes. Através desse percentual, observou-se um grande índice de aceitação dos entrevistados quanto à forma de gestão da administração para gerenciar a empresa, transparecendo uma coordenação eficaz dos colaboradores da empresa, de forma que estas ações melhoram a qualidade dos serviços prestados pela organização.

Houve também um pequeno percentual de discordância quanto ao quesito analisado, que corresponde a $1 \%$ dos entrevistados. No entanto, se sabe que é quase impossível agradar a todos, mas que estas insatisfações merecem a atenção dos gestores para que a empresa atinja um grau de excelência de qualidade nos serviços prestados aos clientes em sua totalidade.

\subsection{DIMENSÃO EMPATIA}

Quanto ao aspecto Empatia, a maioria dos clientes entrevistados $(46,83 \%$ ), que corresponde a 59 pessoas, disse esta satisfeita com atendimento dos funcionários e que os colaboradores demonstram cordialidade e conhecimento para desempenhar suas tarefas. Além disso, 49 pessoas ou (38,89\% dos entrevistados) concordam com a dimensão analisada, indicando que os funcionários se identificam e se sente motivados com o trabalho.

No entanto, 15 entrevistados, referente à $(11,90 \%)$ optaram pela neutralidade em resposta à dimensão analisada; e apenas 01 cliente discordou totalmente e 02 clientes discordaram $(0,79 \%$ e $1,59 \%$, respectivamente), discordaram quanto haver empatia dos colaboradores da Casa Lotérica pesquisada aos atendê-los, como mostra o gráfico 04. 


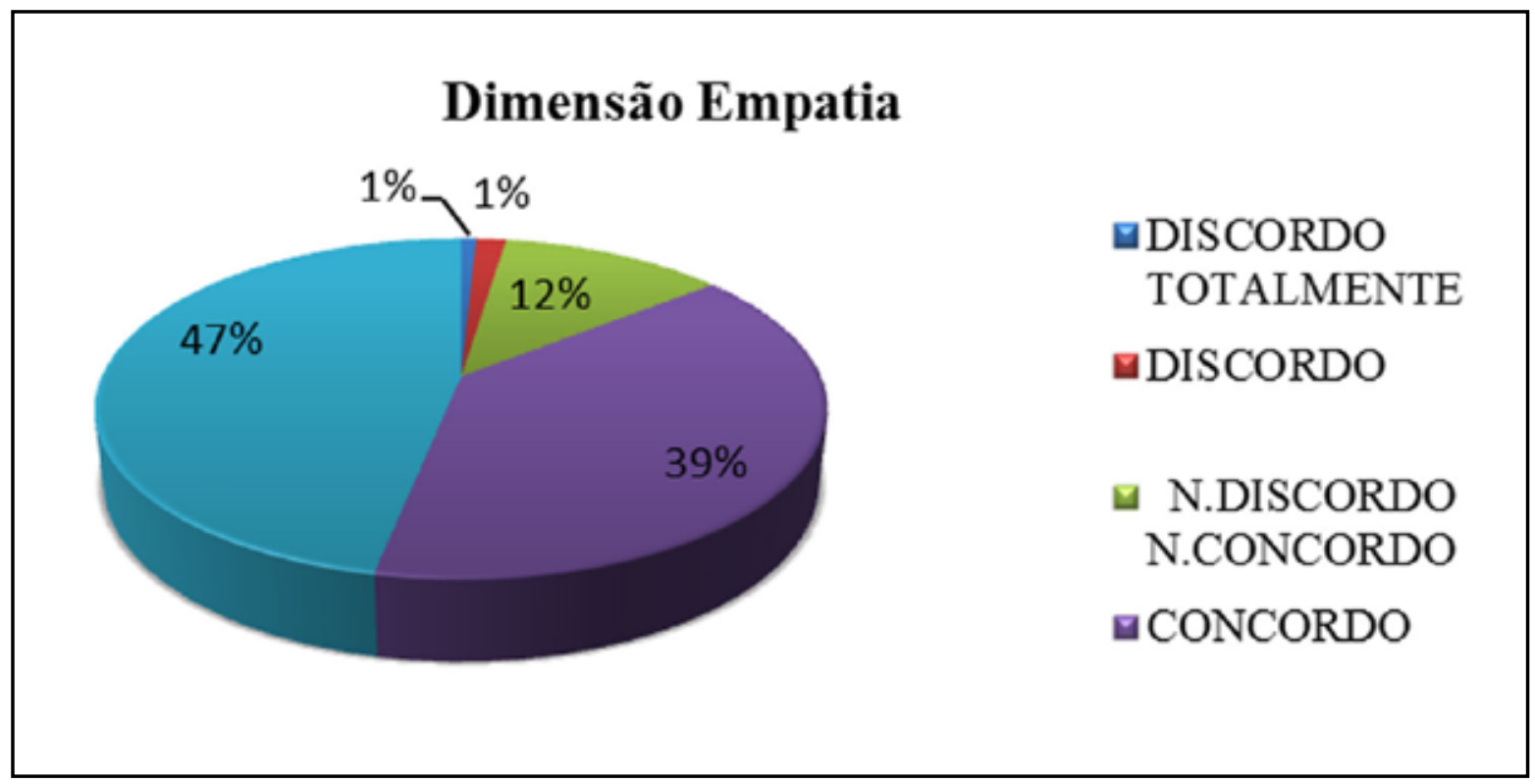

Fonte: Pesquisa direta, (2014).

Os dados apresentam uma concordância total de $85,72 \%$ de aprovação quanto a Empatia dos funcionários da empresa estudada. Porém, ao serem questionados, em relação à discordância, relativa à dimensão empatia, os entrevistados alegam que em algum momento esporádico, se sentiram desconsiderados no atendimento, por parte de algum colaborador da empresa, deixando de se pôr na condição do cliente para tentar resolver determinados problemas.

\subsection{DIMENSÃO DOS ASPECTOS TANGÍVEIS}

Em relação aos aspectos tangíveis, os resultados mostram que a maioria dos clientes entrevistados, $(36,51 \%)$ que corresponde a 46 pessoas, sente-se totalmente satisfeito com as instalações, localização, equipamentos e o estado físico da empresa estudada. Somando-se a este índice de satisfação, 40 pessoas, que corresponde a $31,75 \%$ dos entrevistados, atestam a qualidade das instalações da Casa Lotérica, perfazendo um índice total de $\mathbf{6 8 , 2 6 \%}$ de aprovação quanto à dimensão estudada. Além disso, foi observado que 17 clientes que representam $(13,49 \%)$ dos entrevistados se abstiveram quanto aos aspectos tangíveis da empresa estudada, demonstrando certa neutralidade.

Apesar dos aspectos positivos, houve um percentual total de $18,25 \%$ dos entrevistados que discordaram que a mesma atende as suas expectativas, ou que o ambiente físico da empresa é agradável e que comportam a capacidade de pessoas adequada $(6,35 \%$ discordando totalmente e $11,90 \%$ discordando), como demonstra o Gráfico 05. 


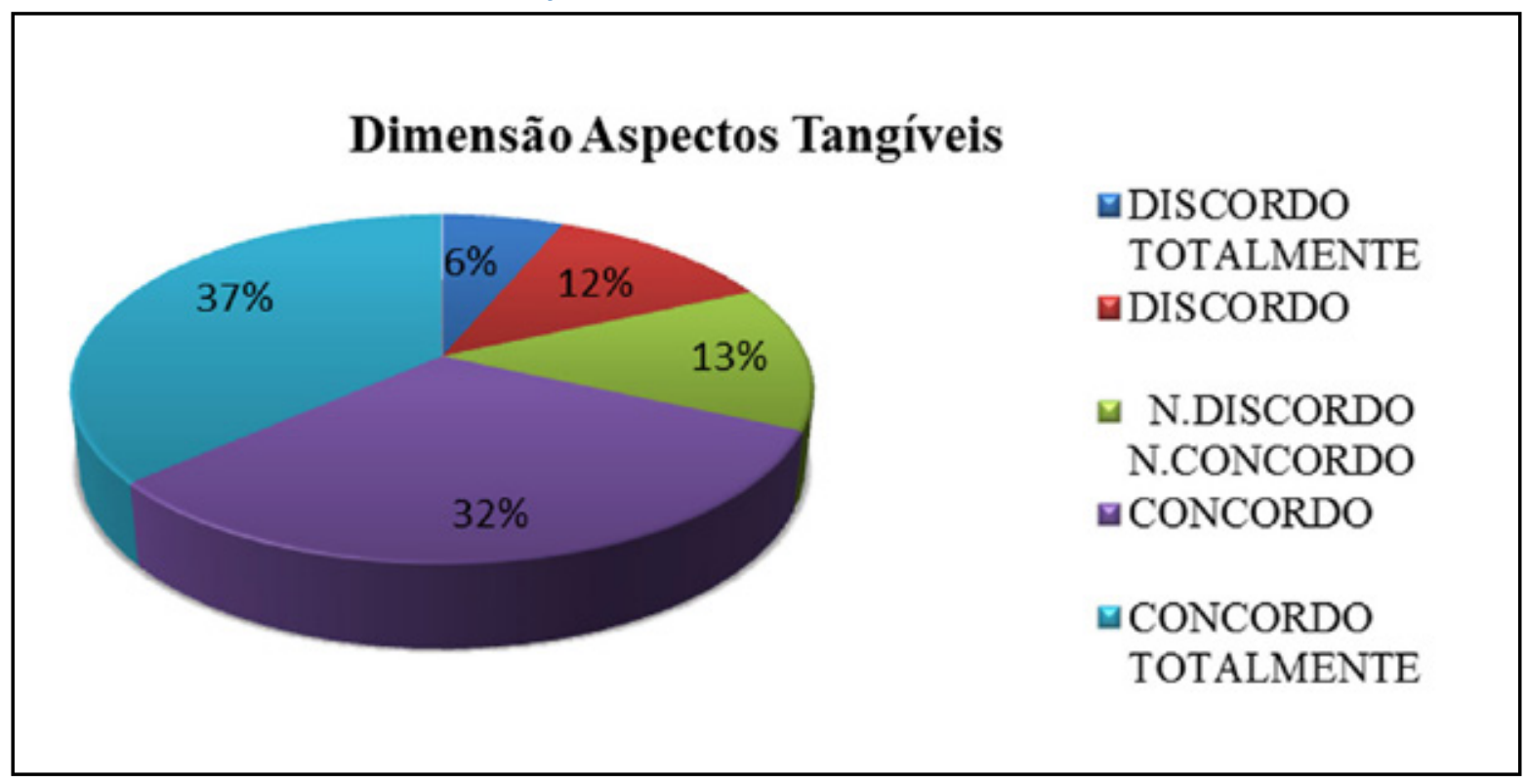

Fonte: Pesquisa direta, (2014).

Considerando os percentuais demonstrados pela Tabela e Gráfico 05, é possível observar que não há uma totalidade quanto aos aspectos tangíveis da Casa lotérica estudada, isto porque, alguns entrevistados alegam que o espaço físico da empresa é insuficiente para atender a demanda e falta uma climatização adequada que proporcione melhor conforto aos clientes.

Estes fatores merecem uma maior atenção por parte da direção da Casa Lotérica, a qual dever investir na ampliação do espaço físico, climatização do ambiente com ar-condicionado e aumentar o número de caixa para satisfazer seus clientes, de modo a fidelizá-los por completo, uma vez que estes fatores são cruciais e influenciam diretamente na percepção da qualidade dos serviços prestados aos clientes da empresa estudada.

\section{CONSIDERAÇÕES FINAIS}

Neste trabalho, como objetivo geral, buscou-se avaliar a qualidade dos serviços prestados por uma Casa Lotérica localizada no munícipio de Cajazeiras/ $\mathrm{PB}$, segundo a percepção de uma amostra de clientes da empresa, por meio de entrevista estrutura, aplicada através de um questionário, através do qual foi possível extrair informações relevantes para aperfeiçoar a qualidade dos serviços prestados pela organização estudada.

Na direção do objetivo geral, alguns objetivos es- pecíficos tiveram de ser alcançados. Para tanto, inicialmente foi delineada a caracterização da empresa, abordando seu histórico e estrutura organizacional. Posteriormente foi observada e analisada a expectativa dos usuários/ clientes, quanto à qualidade dos serviços prestada pela Casa Lotérica, através das seguintes dimensões da qualidade: Confiabilidade, Responsividade, Segurança, Empatia e Aspectos Tangíveis. Logo, após, foi utilizada a Escala de Likert de modo a contribuir para codificar as declarações, qualificadas e revertê-las em dados quantitativos e qualitativos para receberem o tratamento estatístico adequado.

Desta forma, ficou evidente que dentre as cinco dimensões que permeiam a qualidade dos serviços, a dimensão Aspectos Tangíveis (68,36\%) obteve o menor conceito na percepção dos clientes quanto à qualidade dos serviços ofertados, merecendo melhor atenção dos gestores da Casa Lotérica estudada, no intuito de minimizar os resultados negativos e maximizara a qualidade contínua dos serviços prestados pela empresa.

Fica como recomendação à direção da Casa Lotérica fazer investimentos na ampliação do espaço físico, climatização do ambiente da empresa com ar-condicionado e aumentar o número de caixa para satisfazer seus clientes, de modo a fidelizá-los por completo, uma vez que estes fatores são cruciais e influenciam diretamente na percepção 
da qualidade dos serviços prestados aos clientes da empresa estudada.

Ademais, a pesquisa mostrou que o índice de aprovação da qualidade dos serviços prestados pela empresa é maior evidente nas dimensões: Confiabilidade (75,39\%), Responsividade (85,71\%), Segurança $(\mathbf{8 2}, 54 \%)$ e Empatia $(\mathbf{8 5 , 7 2 \%})$ que obtiveram o maior conceito de qualidade segundo a percepção dos clientes pesquisados, constatando, em parte, pelo público usuário pesquisado a credibilidade da qualidade nos serviços prestados pela Casa Lotérica, no tocante a estes requisitos.

Portanto, a qualidade dos serviços prestados pela Casa lotérica em questão, em sua totalidade, teve uma boa avaliação segundo a percepção de seus clientes, no qual, o nível de expectativa que a clientela possui em relação aos serviços ofertados pelo empreendi- mento se sobrepõe a percepção dos mesmos, o que impõe a empresa estudada se empenhar e aprimorar seus pontos fracos, transformando os resultados desta pesquisa numa fonte de subsídios para traçar estratégias, buscar a melhoria contínua da qualidade de seus serviços ofertados e aumentar ainda mais a sua participação do mercado, fidelizando ainda mais seus clientes, garantindo assim, um futuro próspero e promissor.

A limitação da pesquisa foi em decorrência do tempo disponível dos clientes para responder aos questionários, realizado durante o tempo de espera na fila de atendimento. Como também devido o mesmo ter sido aplicado com apenas 126 clientes, parâmetro este tomado devido a restrições de custo e tempo que inviabilizariam a projeção dos resultados para toda base dos clientes da Casa Lotérica estudada.

\section{REFERÊNCIAS}

BRANDÃO JÚNIOR, Antônio; LIRA, Waleska Silveira; GONÇALVES, Geuda Anazile da Costa. A satisfação do cliente como base para a Qualidade em Serviços: O Caso de um Supermercado de pequeno porte. Revista Eletrônica Qualit@s. v. 3, n. 1, Campina Grande/PB, 2004.

GIL, A. C. Métodos e técnicas de pesquisa social. 5. ed., São Paulo: Atlas, 2006.

ISHIKAWA, Kaoru. Controle de Qualidade Total. In: ISHIKAWA, Kaoru. Á maneira japonesa. 6 ed. Rio de Janeiro: Campus, 1997. p. $45-86$.

MARCONI, Marina de Andrade; LAKATOS, Eva Maria. Fundamentos de metodologia científica. 6. ed. São Paulo: Atlas 2008.

LAS CASAS, Alexandre Luzzi. Qualidade Total em Serviços. São Paulo: Atlas, 2008.

MAXIMIANO, A. C. Amaru. Teoria Geral da Administração. 2. ed. São Paulo, Atlas, 2012.

PALADINI. Edson Pacheco. Gestão da Qualidade: teoria e prática. 2. ed. São Paulo: Atlas, 2004.

PARASURAMAN, A.; ZEITHAML, V. A.; BERRY, L. L. A conceptual model of services quality and its implication for future research. Journal of Marketing, v. 49, n. 4, p. 41-50, 1985.

PINHEIRO, Orlene Dantas. Qualidade dos Serviços: avaliação dos clientes quanto à prestação de serviços em um supermercado. Monografia. Curso de Bacharelado em Administração. Faculdade São Francisco da Paraíba - FASP, Cajazeiras/PB, 2012.

OLIVEIRA, Otávio J. (org). Gestão da qualidade: tópicos avançados. São Paulo: Thompson Learning, 2012.

Silva, A. M. S.; CORREIA, A. M. M.; HIDROGO, A. A. A. A gestão da qualidade e a prática de responsabilidade social - uma análise qualitativa dos serviços prestados pelo programa de visitas de uma indústria calçadista na Paraíba na percepção do público. Anais do XIV SIMPEP - Simpósio de Engenharia da Produção. UNESP, v.1, n.10, Bauru, 2007. 


\section{raUnP}

SILVA, E. L; MENEZES, E. M. Metodologia da pesquisa e elaboração de dissertação. 4 ed. rev. atualizada. Florianópolis: UFSC, 2005.

SLACK, Nigel. et al. Administração da produção. Ed. compacta. São Paulo: Atlas, 2009.

SPINA, Daniele Thomazelli; GIRALDI, Janaina de Moura Engracia; OLIVEIRA, Marcio Matos Borges de. A influência das dimensões da qualidade de serviços na satisfação do cliente: um estudo em uma empresa do setor de controle de pragas. REGE, São Paulo - SP, Brasil, v. 20, n. 1, p. 93-112, jan./mar. 2013. 